\section{Erratum}

https://doi.org/10.11646/zootaxa.5091.4.7

http://zoobank.org/urn:1sid:zoobank.org:pub:61106E29-1E19-416B-A606-A73D92D0BF73

\title{
CHRISTOPHER CRUZ-GÓMEZ (2021) A new genus and seven new species of chrysopetalids (Annelida, Chrysopetalidae) from the Tropical Eastern Pacific. Zootaxa, 5068: 001-059.
}

In the material and methods section (page 4), the name of the species for which a neotype is proposed should be read Paleanotus purpurea instead of Bhawatsonia purpurea n. comb. The neotype proposal is related to the speciesgroup name P. purpurea Rioja, 1947, basionym of B. purpurea n. comb., whose type material is lost (ICZN 1999, Art. 72.1.2). In page 33, the synonymy section of Bhawatsonia purpurea n. comb. omitted the basionym of the species (P. purpurea) and subsequent references. In the section of Bhawatsonia purpurea (Rioja, 1947) n. comb. (page 33) the synonymy section is missing. This should be as follows:

Paleanotus purpurea Rioja, 1947: 517-519, Figs 1-7._Cruz-Gómez \& Bastida-Zavala 2018: 82-83, Figs 12A-I, 13, 14L, 15I.-Cruz-Gómez et al. 2021: 180, Fig. 4T (key of chrysopetalids from Tropical America). 